\title{
Primary Care Physicians' Conceptualization of Quality in Medicare's Merit-Based Incentive Payment System
}

\author{
Carl T. Berdabl, MD, MS, Molly C. Easterlin, MD, MS, Gery Ryan, PhD, \\ Jack Needleman, PhD, and Teryl K. Nuckols, MD, MSHS
}

Background: While administrators of pay-for-performance may have good intentions, physicians may be reluctant to participate for various reasons, including poor program alignment with realities of clinical practice. In this study, we sought to characterize how primary care physicians (PCPs) participating in Medicare's Merit-Based Incentive Payment System (MIPS) conceptualize the quality of health care to help inform future measurement strategies that physicians would understand and appreciate.

Methods: We performed semi-structured qualitative interviews with a nationwide sample of 20 PCPs in MIPS. We asked PCPs how they would characterize quality and what distinguished exceptional, good, and poor quality. Interviews were transcribed and 2 coders independently read transcripts, allowing data to emerge from the interviews and developing theories about the data. The coders met intermittently to discuss findings, harmonize the coding scheme, develop a final list of themes and subthemes, and aggregate a list of representative quotations.

Results: Participants described quality as consisting of 2 components: (1) evidence-based care that is safe, which included health maintenance and chronic disease control, accurate diagnoses, and guideline adherence, and (2) patient-centered care, which included spending enough time with patients, responding to patient concerns, and establishing long-term relationships founded on trust.

Conclusions: PCPs consider patient-centered care necessary for the provision of exceptional quality. Program administrators for quality measurement and pay-for-performance programs should explore new ways to reward PCPs for providing outstanding patient-centered care. Future research should be undertaken to determine whether patient-centered activities such as forging long-term, favorable patient-physician relationships, are associated with improved health outcomes. (J Am Board Fam Med 2021;34:590-601.)

Keywords: Health Policy, Medicare, Outcomes Assessment, Patient-Centered Care, Pay for Performance, PhysicianPatient Relations, Primary Health Care, Qualitative Research, Quality Improvement

\section{Background}

The primary care physician (PCP) practice environment has been changing rapidly over the last several decades due to many factors, including the development of quality measurement and pay-for-performance programs. ${ }^{1}$ In 2015, for example, Congress
This article was externally peer reviewed.

Submitted 21 October 2020; revised 19 January 2021; accepted 20 January 2021.

From the Department of Medicine, Cedars-Sinai Medical Center, Los Angeles, CA (CTB, TKN); Department of Emergency Medicine, Cedars-Sinai Medical Center, West Hollywood, CA (CTB); University of California, Los Angeles (UCLA) National Clinician Scholars Program (CTB, MCE); Department of Pediatrics, Cedars-Sinai Medical Center (MCE); Division of Neonatal Medicine, Department of Pediatrics, Los Angeles County and University of Southern California Medical Center (MCE); Kaiser Permanente School of Medicine, Pasadena, CA (GR); Department of Health Policy and Management, UCLA Fielding School of Public Health (JN).

Funding: The UCLA National Clinician Scholars program and Cedars-Sinai Medical Center contributed internal funds that made the study possible.

Conflicts of interest: None.
Related work: Results from the same participants and the same interview sessions (but relating to different research questions) are presented in the following manuscript: Berdahl CT, Easterlin MC, Ryan G, Needleman J, Nuckols TK. Primary Care Physicians in the Merit-Based Incentive Payment System (MIPS): A Qualitative Investigation of Participants' Experiences, Self-Reported Practice Changes, and Suggestions for Program Administrators. J Gen Intern Med 2019;34(10):2275-81.

Prior presentations: The research plan was presented as a poster at the National Clinician Scholars Program Annual Research Meeting in Atlanta, GA on November 15, 2016.

Pre-print: This article is available in pre-print at https:// www.researchsquare.com/article/rs-26478/v1.

Corresponding author: Carl T. Berdahl, MD, MS; Department of Medicine, Cedars-Sinai Medical Center, 8700 Beverly Blvd, Becker 113, Los Angeles, CA 90048 (Email: carl.berdahl@csmc.edu). 
passed the Medicare Access and CHIP Reauthorization Act (MACRA), thereby firmly establishing a payment system that alters physician payment based on performance on measures of health care quality and value. ${ }^{2}$ Under MACRA, physicians participate in the Quality Payment Program either through the default pay-for-performance track-the MeritBased Incentive Payment System (MIPS)—or via Advanced Alternative Payment Models, such as risk-bearing accountable care organizations, which reward physicians with a $5 \%$ lump-sum bonus payment. In the first year of the Quality Payment Program, approximately 700,000 physicians participated in MIPS by submitting data related to (1) quality, (2) cost, (3) improvement activities, or (4) use of certified electronic health record technology to the Centers for Medicare and Medicaid Services (CMS). ${ }^{3-5}$ Based on performance on activities in these 4 categories each year, CMS generates composite scores determining whether physicians or groups will receive upward, neutral, or downward payment adjustments 2 years in the future. CMS reported that $94 \%$ of all eligible physicians participated in the first year of MIPS, and 74\% of clinicians reported quality data for a full 12 months. ${ }^{6}$ These statistics demonstrate that the MIPS program affects a substantial number of physicians across the nation, and it has the potential to influence quality of care for millions of patient-physician encounters.

Meanwhile, a countermovement against quality measurement and pay-for-performance programs has been occurring. In a 2015 survey of PCP experiences and reactions to changes in health care payment, $67 \%$ of physicians reported believing that quality measures were having negative or no impact on their ability to provide high-quality healthcare to their patients. ${ }^{7}$ Additionally, some evidence indicates that increased burden of administrative rules and regulations has negatively impacted physician satisfaction, ${ }^{8}$ and that diversion of physician attention from patient-centered concerns may worsen health outcomes. ${ }^{9-11}$ Prominent stakeholders now advocate for measurement parsimony, ${ }^{12}$ a decrease in the number of resources dedicated toward quality measurement, ${ }^{13-15}$ a reduction of administrative burdens for physicians, ${ }^{16}$ and discontinuation of invalid measures. ${ }^{17}$ In particular, the MIPS program has fostered controversy and criticism from physician groups because of the burdens of data collection and reporting, particularly for smaller practices. ${ }^{18-21}$ Thus in a contemporary clinical practice environment characterized by both physician ambivalence to measurement and an expansion of quality measurement activities, there is a need to examine physician conceptualizations of the quality of healthcare so that quality measurement program administrators can align future measurement programs to optimize physician engagement. ${ }^{22,23}$ Thus, our objective was to describe how PCPs characterize the nature of quality in healthcare by performing interviews with PCPs reporting under MIPS.

\section{Methods}

\section{Design, Setting, and Participants}

We conducted a qualitative study using 1-on-one semi-structured interviews with MIPS-eligible PCPs in 2017 and $2018 .{ }^{24}$ To facilitate investigation of a variety of clinical experiences, we recruited PCPs from diverse practice settings across the United States by using maximum variation sampling. ${ }^{25} \mathrm{We}$ considered PCPs who were trained in family medicine or internal medicine to be eligible for the study if they were expected to report under MIPS. We verified MIPS expected reporting status by using an online tool. ${ }^{26}$ PCPs were recruited by word-of-mouth, using a mixture of referrals from study investigators and physician organizations, including the Los Angeles County Medical Association. To ensure a diverse sample of participants, we began each interview with a brief presession survey to obtain information about the physician and his/her practice. As recruitment proceeded, we aimed to fill gaps in our sample by seeking out a specific physician or practice characteristics (eg, small practice, rural setting, etc). Interviews were planned to last approximately 30 minutes (duration range, 13 minutes 45 seconds to 40 minutes 52 seconds), and participants were additionally asked specific questions about the MIPS program as described in a related manuscript. ${ }^{21}$ We provided a $\$ 50$ gift card as compensation for participation.

\section{Description of Interview Sessions}

At the beginning of each interview session, a brief pre-session survey was administered to confirm eligibility for the study, ascertain physician and practice characteristics (self-reported by the physician) to direct maximum variation sampling, and facilitate reporting of the study sample in this manuscript. One author (CTB), an emergency physician and fellowship-trained health services 
researcher with qualitative methods experience, performed all interviews either in person, for participants local to the Los Angeles area, or by telephone, for participants in other regions. Inperson interviews were completed in participants' offices and audio recorded. Telephone interviews were performed using a secure audio recording. The interviewer used a semi-structured interview guide. (See Box 1 for a brief overview of interview questions. Appendix A1 provides the pre-session survey and the full semi-structured interview guide.) A professional transcription service transcribed all interviews. In the results section and appendices, quotes from study participants are annotated with unique participant numbers (e.g. P5 for participant number 5) so that readers can discern whether multiple quotes came from same or different participants. It should be noted that a related publication focusing on the MIPS policy itself describes results from the same interview sessions with the same PCPs. ${ }^{24}$

\section{Analysis}

We utilized a 2-step process to allow data to emerge from the semi-structured interviews, developing theories about the data and maintaining a log of ideas about the meaning of its content. Two coders, CTB (described above) and MCE (pediatrician and fellowship-trained health services researcher), independently read transcripts of the first 5 interviews and flagged all instances of responses related to the study questions using the text analysis software Atlas.ti Version 8 (ATLAS.ti Scientific Software Development GmbH, Berlin, Germany). We had an initial meeting to discuss and harmonize our coding schemes based on the emerging themes. We reviewed and coded through the eighteenth interview and then met again to discuss themes and subthemes. At this point, we decided that thematic saturation had likely been reached. We coded 2 final interviews without discovering new themes, confirming that thematic saturation had been achieved. We met once more to discuss findings and develop a final list of themes and subthemes, aggregating representative quotations from participants. We also assigned participants to subgroups to help facilitate exploratory analyses for participants with different practice characteristics. All study findings were additionally validated through discussions with senior co- authors (TKN, GR, JN) and others named in the acknowledgements.

\section{Ethics}

Institutional review boards at Cedars-Sinai Medical Center and the University of California, Los Angeles (UCLA) approved the study protocol. We obtained verbal consent from all study participants, which included consent for audio recording.

\section{Results}

\section{Descriptive Characteristics of the Sample}

Twenty PCPs participated in the study between November 2017 and June 2018. Eighteen of the 20 PCPs were board-certified at the time of interview (7 in family medicine and 11 in internal medicine). Nine physicians worked in small practices (groups of fewer than fifteen providers), and 5 worked in rural areas. Most PCPs worked in practices where most income arose from fee-for-service payment arrangements. Table 1 describes participants and their practice environments in further detail for the sample overall, and Appendix A3 provides participant-level practice characteristics that can be matched with quotes that seem in the remainder of the manuscript.

\section{Physician Conceptualizations of Health care Quality: Overview}

A conceptual framework describing PCPs' characterization of quality in health care emerged via inductive analysis of the interviews. When asked to define health care quality, many respondents described the concept as consisting of 2 components: (1) evidenced-based care that is safe, and (2) patient-centered care that is responsive to individual patients' needs. Most PCPs described that their first responsibility was to deliver evidence-based care, which consisted of routine health maintenance, chronic disease management, care consistent with current recommendations, accurate diagnoses, and high-value care. Providing evidence-based care was viewed as necessary, but not sufficient, for the provision of exceptional health care. Delivering evidence-based care along with patient-centered care was viewed as exceptional. Physicians often described examples of outstanding care as offering particularly timely care, responding to patients' 
Table 1. Continued

\begin{tabular}{|c|c|c|}
\hline Question & Response & $\mathrm{N}(\%)$ \\
\hline \multicolumn{3}{|c|}{ How are you primarily compensated? } \\
\hline & Fee for service & $9(45)$ \\
\hline & Capitation & $2(10)$ \\
\hline & Salary & $9(45)$ \\
\hline \multicolumn{3}{|c|}{$\begin{array}{l}\text { What percent of your practice's income comes from fee-for-service } \\
\text { payments? }\end{array}$} \\
\hline & 0 & $1(5)$ \\
\hline & $1-24$ & $3(15)$ \\
\hline & $25-49$ & $1(5)$ \\
\hline & $50-74$ & $2(10)$ \\
\hline & $75-99$ & $9(45)$ \\
\hline & 100 & $3(15)$ \\
\hline & Not sure & $1(5)$ \\
\hline \multicolumn{3}{|c|}{ Do you have staff on hand to help manage quality of care? } \\
\hline & Yes & $17(85)$ \\
\hline & No & $3(15)$ \\
\hline \multicolumn{3}{|c|}{$\begin{array}{l}\text { Did you or your group participate in the Physician Quality Reporting } \\
\text { System (PQRS)? }\end{array}$} \\
\hline & Yes & $12(60)$ \\
\hline & No & $6(30)$ \\
\hline & I don't know & $2(10)$ \\
\hline
\end{tabular}

individual needs, or advocating for a patient under special circumstances. See Figure 1 for a graphical depiction of this conceptual framework, Table 2 for a complete list of themes and subthemes, and Appendix A2 for a list of sample quotes exemplifying all subthemes. The following paragraphs explore the components of evidence-based and patient-centered care in further detail.

\section{Component 1: Evidence-Based Care That is Safe}

When asked to provide specific examples of high-quality care, many participants focused on providing recommended health maintenance: "I believe that there are certain elements of providing care that are standard of care and that are proven to be beneficial to patients. Flu vaccine, pneumonia vaccine, vaccines in general, cancer screenings, like breast screening, colon cancer screening, cervical cancer screening." (P4) Participants also commonly mentioned control of chronic disease as important to health care quality: "When a physician is taking care of a patient with diabetes... The patient should come in at 1 month, then 3 months, then 6-month intervals. [The physician] should know what blood work they are getting at that interval. At every visit, [the physician] should take off their shoes and socks, check monofilaments on them, make sure that the medications are reconciled, and that this information is communicated with the patient's other physicians. This should be a set protocol." (P12) Many physicians mentioned that they relied on evidence-based recommendations from trusted organizations to guide diagnostic and treatment decisions, stating that it was the PCP's responsibility to stay up-to-date with these standards: "I would say that practices [providing high-quality care are practices that are] making every effort to ensure that they are meeting the standard of care as put forth from wellestablished bodies such as US Preventive Services Task Force, from [Medicare], and from our own organizations such as the American Academy of Family Physicians." (P6)

Participants also expressed the belief that safety was an important dimension of health care quality: They strived to make accurate diagnoses and avoid low-value care to ensure that patients received high-quality, evidence-based care. One PCP explained that making an accurate diagnosis could be challenging, but also believed doing so consistently was a physician's responsibility: "Everybody 
Figure 1. Conceptual Framework: What Makes The Quality Of Health Care Exceptional?

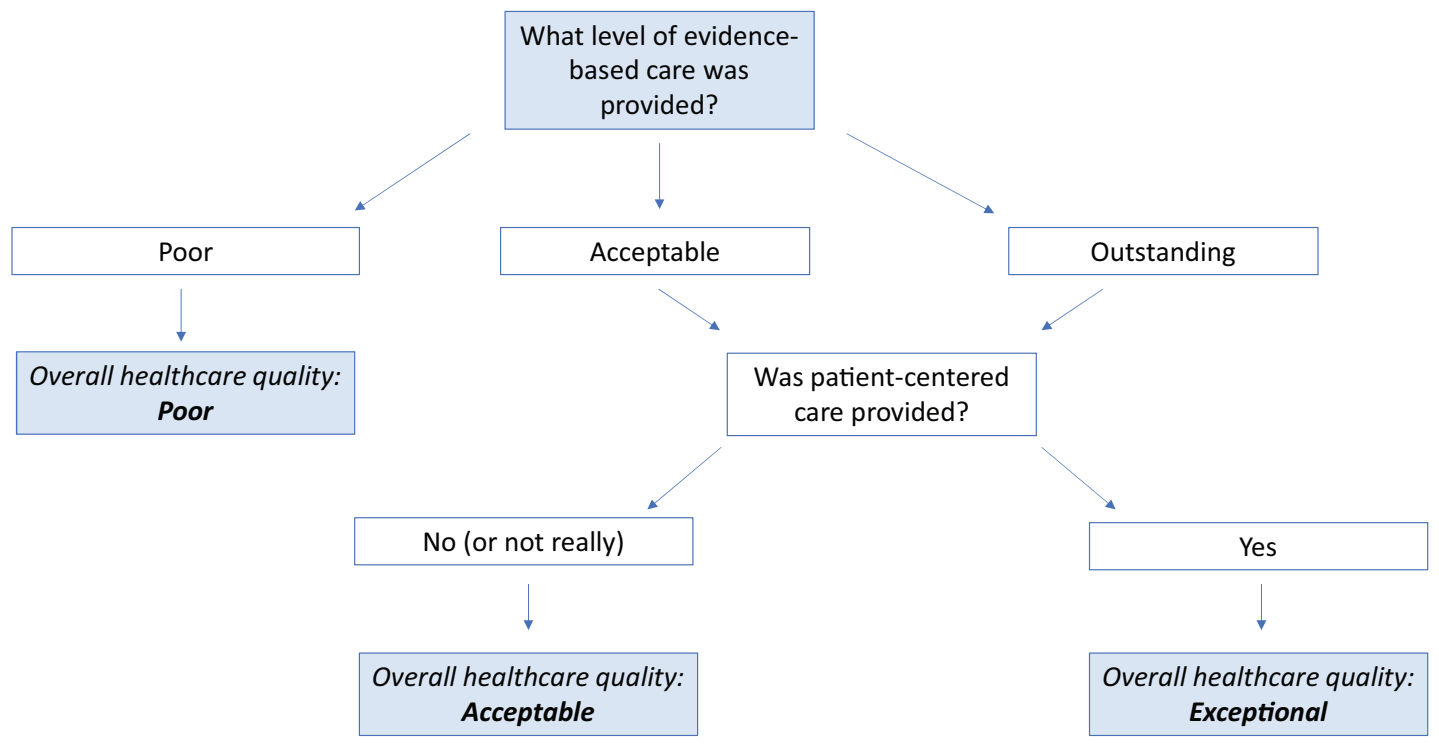

can do checklist medicine and check [a hemoglobin $\mathrm{A} 1 \mathrm{C}$ ] twice this calendar year. [On the other hand,] when you have a patient with a difficult diagnosis which you establish and come up with an effective treatment for-now that is good care." (P11) There was also a sense among participants that low-value care could be harmful to patients, either because of costs or adverse consequences related to testing or treatments that were not indicated. One PCP provided an example by describing that his grandmother might demand care, but the right course of action was to withhold care in cases where potential harms outweighed potential benefits: "My grandma was a very wealthy person and she was very demanding. Basically, she would want you to forget about standards in health care and spend every health care dollar on her and waste everything on her to get every test possible, which is absolutely not right because [it is wasteful and potentially harmful.]" (P12) See Table 2 for more examples of subthemes that were categorized as related to evidence-based care.

\section{Component 2: Patient-Centered Care}

Many respondents reported believing that a good PCP provided patient-centered, personalized service. In other words, simply providing evidence-based medicine was not enough because patients needed and deserved excellent service as well. One respondent relayed, "I think broadly about right care, right place, right time for the patient, in a patient-centered way. I mean, I think in my own terms, I would think of quality care being all the care you need and none of the care that you do not need, delivered in a personalized way, in accord as much as possible with the best available evidence and done efficiently and in the flow of...working within the flow of patients' lives." (P16) Several participants mentioned that helping patients achieve personalized goals was more important than scoring well on quality measures: "I think our job as doctors is to help patients achieve their life goals, their health-related life goals. So for me, that is what quality is about....At the end of the day, if I am achieving perfect scores [on quality measures] but not meeting the patients' goals, helping advance what they want, I am not doing a good job." (P5) Providing unusually timely care was a subtheme that many participants discussed. PCPs tended to believe that providing easy, open access to patients was an important way to systematically deliver outstanding care: "I personally give my patients my email address so they can directly contact me with any concerns without being filtered by my staff. I try to have good hours, leave slots for urgent care, essentially have them be able to access me so that they can get care." (P1) Finally, ensuring that patients actually received the care that PCPs prescribed was a common challenge that PCPs noted: "I think developing systems as an individual or with teams in your clinic to ensure good follow-up for patients. So, seeing patients and tracking patients over time-Looking across your 
Table 2. List of Study Themes, Associated Study Sub-Themes, and Relevant Institute of Medicine Domains

\begin{tabular}{lll}
\hline Study Themes & \multicolumn{1}{c}{ Study Sub-themes } & Relevant IOM Domain \\
\hline Evidence-based care that is safe & Providing recommended health maintenance & Effective \\
& Controlling chronic diseases & Effective \\
& Knowing and following current recommendations & Effective \\
& Making accurate diagnoses; not missing diagnoses & Safe \\
& Delivering efficient care (not too much and not too little) & Efficient \\
& Providing personalized care & Patient-centered \\
Patient-centered care & Providing well-coordinated care & Patient-centered \\
& Spending enough time with patients & Patient-centered \\
& Responsiveness to patient concerns & Patient-centered \\
& Being an advocate for patients & Patient-centered \\
& Understanding social needs & Patient-centered \\
& Helping patients achieve their goals & Patient-centered \\
Prioritizing quality of life & Patient-centered \\
Listening to patients & Patient-centered \\
Educating patients & Patient-centered \\
Establishing trust and long-term relationships & Patient-centered \\
Demonstrating compassion & Providing timely care & Timely
\end{tabular}

IOM, Institute of Medicine.

Note: Participants did not mention the concept of equity, which is one of 6 IOM Domains of the quality of healthcare.

Box 1: Key questions for study participants.

What do you consider to be "good" quality of care? What does it "look" like?

What is exceptional quality of care, and how is it different than good quality of care?

What is low quality care, and how is it different than good quality of care?

What kinds of things can a primary care physician do to ensure he/she is providing exceptional quality of care?

panel... and trying to be systematic and proactive about having patients come back in or refer to sites of care expeditiously and effectively." (P16)

Several PCPs spoke about the importance of establishing long-term relationships with patients founded on trust. For example, 1 physician in a large group practice mentioned, "What people do not get is that if patients go to the person that they trust, they are more likely to be adherent to their medication or adherent to whatever regimen, if they know and trust the physician.” (P1) PCPs considered demonstrating caring and compassion to be important, and they believed that this helped establish good rapport with patients: "I think the patients are looking for someone who will listen, someone who seems to be interested in the problems that they are presenting... Obviously, they want you to be knowledgeable and compassionate and timely and everything else, but I think patients want to be listened to and taken more seriously than anything else." (P20) PCPs perceived a contrast between evidence-based care, which tends to be feasible to measure, and patient-centered care, which tends to be hard to measure. Several physicians lamented that measurement priorities may be misaligned simply because measurement of patient-centered care is challenging: "The quality movement has been perverted to a kind of big data enterprise now and really, I think the focus of primary care is actually about relationships and building sort of meaningful relationships with people over time.” (P18)

\section{Conceptualizing Exceptional and Poor Health care Quality}

To further refine the PCP definition of health care quality, we asked participants to describe what separated exceptional care from good care. In describing exceptional care, respondents tended to emphasize the patient-centered component of quality even more, including relationship-building and shared decision making. One respondent explained, "I think, also, there's that human component that is hard to measure, the connection that people feel with their primary care doctor for those who feel connected." (P10) Respondents also tended to include immediate access and timely responses in 
their definition of exceptional care, whether that was a patient's ability to obtain an appointment immediately or engage in brief conversations with PCPs by phone or e-mail: "I think it is about hearing people and really listening, engaging them, letting them know that you are there, even when they are not in the office. So they can run something by me either by e-mail or call my office. I guess for me, exceptional care has been really more about the relationship." (P1) Some respondents included patient advocacy in their definition of exceptional health care quality: "When I think of a doctor who is exceptional, I just think of someone who is an awesome patient advocate and making sure that the patients get what they need to the best of their ability." (P4)

Finally, we asked PCPs to distinguish poor care from good care. Participants cited faults in evidenced-based care that resulted in missed diagnosis or inappropriate treatment: "I guess I would say low quality of care, if I meet people who have been with other physicians, I would say honestly, either under or overtreatment.... So, I see people who are getting annual chest $\mathrm{x}$-rays and cardiac stress tests for no reason. So, I find that as painful as people who are not receiving great care. So, I will get people who have never been asked if they have had their screening colonoscopy and they are 60 or are overdue for screening mammograms." (P1) Another participant agreed, also adding that lack of care coordination contributes to low-quality care: "So, I think low quality of care could be a couple of different things. One could be-unfortunately, I have seen providers in practice that are not maybe following evidence-based recommendations or maybe do not have the skill level to address the problem they are trying to address but they are not kind of seeking out help. So, I guess I have seen misdiagnoses, mistreatments, so that is low quality of care definitely. Then I think also the other piece of it could be that they tend to just really not follow up well with their own patients and not coordinate care back to the primary care doctor well. That can sometimes result in low quality of care too because things that they recommend never get conducted.” (P9)

\section{Differences in Responses according to Practice Characteristics}

While the study was not designed to detect differences in quality conceptualization by practice characteristics, certain themes emerged more commonly during interviews with PCPs in large versus small practices and urban versus rural settings. PCPs from large practices more frequently quoted pre-existing definitions of quality and specific quality measures. For example, 1 participant from a large practice stated, "I learned that quality equals appropriateness times the combination of outcomes and service divided by waste." (P15) Another PCP from a large practice mentioned that common measures included measures related to administration of "flu vaccine, pneumonia vaccine, vaccines in general, cancer screenings, like breast cancer screening, colon cancer screening, cervical cancer screening...A1C that is as close to normal, having blood pressures at certain levels, etc.” (P4) PCPs from small practices more commonly responded with definitions of quality that could be considered more practical rather than rule-based, for example: "Patient stable, kept out of the hospital, and medical conditions controlled" (P2) and "spending enough time, being responsive, being accessible, and having your delivery model be able to provide evidence-based medicine in a timely manner." (P3)

PCPs in rural settings more commonly mentioned that a patient's socioeconomic status should be considered when interpreting performance on quality measures ( 2 of 5 rural vs 1 of 9 urban). For example, 1 PCP from a small practice in the rural South mentioned, "I think it is almost impossible to rate quality unless you can find a way to do it by socioeconomic status. Here's the deal: Our A1C goal for our accountable care organization is 9. It is hard to get a lot of them under a 9. I've got a son that is doing a residency in the Midwest. They never see 1 over 8." (P14) The 1 urban PCP who mentioned socioeconomic status and its relevance to quality measurement referred to challenges involved with caring for homeless patients: "It may be that they are homeless and it does not make sense to have them on 9 medications a day for their heart failure, because there's no way they can possibly be compliant. So, we may go for a simpler regimen that makes more sense to them.” (P5)

\section{Discussion}

Quality of health care is notoriously challenging to define, and varying stakeholders have often defined it differently. In this qualitative investigation of PCP opinions about the nature of health care quality, participants revealed that they conceptualize health care quality as having 2 components: (1) 
evidence-based care that is safe and (2) patient-centered care. Moreover, evidence-based care that is safe is necessary but not sufficient in the provision of exceptional care. According to our panel of physicians, patient-centered care is an important component of the care experience, especially the establishment of long-standing patient-physician relationships built on trust. Understanding how physicians conceptualize quality is important to optimizing engagement in quality improvement efforts. $^{23}$

The Institute of Medicine identified 6 domains of health care quality: safety, effectiveness, timeliness, patient-centeredness, equity, and efficiency. ${ }^{27}$ Physicians in our study identified all these subthemes except equity, and it is difficult to know whether this subtheme might have emerged with a larger sample size or a different sample of PCPs. The framework that emerged from our data (Figure 1) seems to be a simplified version of the framework from the Institute of Medicine (IOM), though our framework highlights the finding that PCPs believe the provision of patient-centered care is what distinguishes exceptional care from good care. Alternative conceptual frameworks relating to the quality of health care have been promulgated by various organizations including the Council of Europe, ${ }^{28}$ the Organization for Economic Cooperation and Development (OECD), ${ }^{29}$ the World Health Organization, ${ }^{30}$ and the European Commission. ${ }^{31}$ The OECD reviewed these models in a 2019 publication and proposed 3 core dimensions of quality that align with our components: effectiveness, safety (which we refer to collectively as "evidence-based care that is safe"), and responsiveness ("patientcenteredness"). ${ }^{32}$

Our interviews revealed physician beliefs that providing patient-centered care was necessary for care to be exceptional. If MIPS is intended to distinguish exceptional from good care, it may underemphasize the provision of patient-centered care, probably due to lack of availability of valid measures. A 2018 panel convened by the American College of Physicians (ACP) to review MIPS measures relevant to PCP practice found that only $37 \%$ (32 of 86 ) were valid measures of physician performance. ${ }^{17}$ Of 86 total measures, the only 1 relevant to patient-centered care was the Consumer Assessment of Healthcare Providers and Systems (CAHPS) for MIPS measure. This measure assesses Medicare beneficiaries' experiences with the care experience including interactions with physicians, office staff, care coordination, and more. ${ }^{33}$ The ACP panel deemed CAHPS for MIPS to have uncertain validity in measuring physician performance for several reasons, including limited physician influence on components of the measure and the measure's questionable relationship with health outcomes. ${ }^{17}$ Moreover, submission of the CAHPS measure is limited to groups and virtual groups, and it requires MIPS participants to pay for a CMSapproved vendor to administer the survey, ${ }^{34}$ further constraining physician participation. Thus, to better align the MIPS program with physician conceptualization of what makes quality outstanding in the minds of PCPs, program administrators could consider providing financial support for CAHPS survey administration, developing new CAHPS measures that assess longitudinal relationships between physicians and patients, and providing new types of incentives for patient-centered care.

Our findings have additional implications for quality measurement and pay-for-performance movements because our participants communicated that PCPs believe long-standing, trustbased relationships are important for the provision of exceptional health care. Our findings may provide primary care providers with talking points to guide payers, professional societies, and others to create a more robust data collection process and provider support program going forward. Further research is warranted to verify our findings across a larger population of PCPs and determine whether rewarding performance on other aspects of patient-centered care, such as the development of long-term patient-physician relationships founded on trust, could improve health outcomes for patients.

Moving beyond the direct implications of our study, a 2018 FAMA viewpoint article titled "Professionalism, Performance, and the Future of Physician Incentives" suggested that program administrators consider adoption of new incentives that are more local and more directly relevant to daily clinical practice. For example, (1) clinicians could be incentivized to develop and select their own quality goals; (2) the level of performance measurement could be altered so that interdisciplinary clinical teams are the focus 
rather than clinicians, which could lead to improved team-based care and improved physician satisfaction; and (3) nonfinancial rewards could be prioritized, which would capitalize on PCP physician intrinsic motivation. In our opinion and considering our study's findings, exploring incentives such as these could help align future quality measurement and pay-for-performance programs with PCP priorities. ${ }^{35}$

\section{Limitations}

Our study has several limitations. First, smallsample qualitative studies are useful for developing theories and identifying questions that should undergo further inquiry. Therefore, this study may be limited in its generalizability, though we attempted to minimize this risk by recruiting PCPs in different areas across the national and different practice environments. Second, because we decided to use maximum variation sampling, the characteristics of our sample may not reflect those of the population of physicians nationwide. Third, word of mouth was used to recruit PCPs in our sample, so our study population may be biased despite our best efforts to seek out diversity in physician and practice characteristics. Fourth, our interviews included questions about the MIPS program, and recruiting physicians for a study involving questions about a quality measurement program may have biased responses about the nature of quality in health care. Fifth, we report subgroup analyses (large vs small practices, rural vs urban setting) to explore our data completely and generate hypotheses for future inquiry; however, the study was not designed to facilitate subgroup analyses, so these analyses should be interpreted with caution. Finally, though we made attempts to ensure rigor and limit biases by employing reflexivity and bracketing ${ }^{33}$ during study design, recruitment, data collection, and analysis, there remains a risk that investigator and coder biases may have limited the reliability or validity of our findings.

\section{Conclusions}

PCPs consider patient-centered care to be necessary for the provision of exceptional quality in health care. Program administrators for quality measurement and pay-for-performance programs should explore new ways to reward PCPs for providing outstanding patient-centered care. Future research should be undertaken to determine whether patient-centered activities such as forging long-term, favorable patient-physician relationships, are associated with improved health outcomes.

The authors wish to thank John Jenrette, MD; Clement Yang, MD; Stephen Deutsch, MD; Caroline Goldzweig, MD, MSHS; Mark Noah, MD; and the Los Angeles County Medical Association for their assistance with study design and recruitment activities. The authors wish to thank Anish Mahajan, MD, for his thoughtful comments about the implications of the study results.

To see this article online, please go to: http://jabfm.org/content/ 34/3/590.full.

\section{References}

1. Laiteerapong $\mathrm{N}$, Huang ES. The pace of change in medical practice and health policy: collision or coexistence? J Gen Intern Med 2015;30:84852.

2. Centers for Medicare and Medicaid Services, US Department of Health and Human Services. Medicare Access and CHIP Reauthorization Act of 2015. Pub. L. No 2015;114:2015.

3. Centers for Medicare and Medicaid Services, US Department of Health and Human Services. MeritBased Incentive Payment System (MIPS) Overview. 2020. Available from: https://qpp.cms.gov/mips/ overview. Accessed April 9, 2020.

4. Centers for Medicare and Medicaid Services, US Department of Health and Human Services. Medicare Program; Merit-Based Incentive Payment System (MIPS) and Alternative Payment Model (APM) Incentive Under the Physician Fee Schedule, and Criteria for Physician-Focused Payment Models. Final rule with comment period. Fed Regist 2016;81:77008-831. Available from: https://www.federalregister.gov/ documents/2016/11/04/2016-25240/medicare-programmerit-based-incentive-payment-system-mips-andalternative-payment-model-apm. Accessed May 4, 2021.

5. Verma S. Centers for Medicare and Medicaid Services, US Department of Health and Human Services. Quality Payment Program (QPP) Year 1 Performance Results. 2018. Available from: https:// www.cms.gov/blog/quality-payment-program-qppyear-1-performance-results. Accessed June 3, 2019.

6. Centers for Medicare and Medicaid Services, US Department of Health and Human Services. 2017 Quality Payment Program Reporting Experience. 2018.

7. Commonwealth Fund; Henry J. Kaiser Family Foundation. Primary Care Providers' Views of Recent Trends in Health Care Delivery and Payment. Findings from the Commonwealth Fund/ Kaiser Family Foundation 2015 National Survey of 
Primary Care Providers. Issue Brief (Commonw Fund). 2015;24:1-13.

8. Friedberg MW, Chen PG, Van Busum KR, et al. Factors affecting physician professional satisfaction and their implications for patient care, health systems, and health policy. Rand Health Q 2014;3:1.

9. Marmor RA, Clay B, Millen M, Savides TJ, Longhurst CA. The impact of physician EHR usage on patient satisfaction. Appl Clin Inform 2018;9:11-4.

10. Panagioti M, Geraghty K, Johnson J, et al. Association between physician burnout and patient safety, professionalism, and patient satisfaction: a systematic review and meta-analysis. JAMA Intern Med 2018;178:1317-30.

11. Kuhn T, Basch P, Barr M, Yackel T. Medical Informatics Committee of the American College of Physicians. Clinical documentation in the 21 st century: executive summary of a policy position paper from the American College of Physicians. Ann Intern Med 2015;162:301-3.

12. Meyer GS, Nelson EC, Pryor DB, et al. More quality measures versus measuring what matters: a call for balance and parsimony. BMJ Qual Saf 2012;21: 964-8.

13. Casalino LP, Gans D, Weber R, et al. US physician practices spend more than $\$ 15.4$ billion annually to report quality measures. Health Aff (Millwood) 2016;35:401-6.

14. Meltzer DO, Chung JW. The population value of quality indicator reporting: a framework for prioritizing health care performance measures. Health Aff (Millwood) 2014;33:132-9.

15. Panzer RJ, Gitomer RS, Greene WH, Webster PR, Landry KR, Riccobono CA. Increasing demands for quality measurement. JAMA 2013;310:1971-80.

16. Centers for Medicare and Medicaid Services, US Department of Health and Human Services. Reducing Burden. 2019 Available from: https://www.cms.gov/ About-CMS/Components/CPI/Reducing-Burden. Accessed May 4, 2021.

17. MacLean CH, Kerr EA, Qaseem A. Time Out Charting a Path for Improving Performance Measurement. N Engl J Med 2018;378:1757-61.

18. Medicare Payment Policy: Report to Congress. Washington, DC: Medicare Payment Advisory Commission; 2018. Available from: http://www.medpac.gov/docs/ default-source/reports/mar18_medpac_entirereport_sec. pdf?sfvrsn=0. Accessed May 4, 2021.

19. Firth S. MIPS Takes a Beating at MedPAC - Medicare advisory panel says it needs to go. MedPage Today. 2017. Available from: https://www.medpagetoday.com/ publichealthpolicy/medicare/68362. Accessed April 9, 2020.

20. Soylu TG, Goldberg DG, Cuellar AE, Kuzel AJ. Medicare access and CHIP reauthorization act in small to medium-sized primary care practices. J Am Board Fam Med 2020;33:942-52.
21. Berdahl CT, Easterlin MC, Ryan G, Needleman J, Nuckols TK. Primary care physicians in the MeritBased Incentive Payment System (MIPS): a qualitative investigation of participants' experiences, self-reported practice changes, and suggestions for program administrators. J Gen Intern Med 2019;34:2275-81.

22. Liao JM, Shea JA, Weissman A, Navathe AS. Physician perspectives in year 1 of MACRA and its merit-based payment system: a national survey. Health Aff (Millwood) 2018;37:1079-86.

23. Wiig S, Aase K, von Plessen C, For QUASERteam, et al. Talking about quality: exploring how 'quality' is conceptualized in European hospitals and healthcare systems. BMC Health Serv Res 2014;14:478.

24. Barriball KL, While A. Collecting data using a semi-structured interview: a discussion paper. J Adv Nurs 1994;19:328-35.

25. Patton MQ. Qualitative research \& evaluation methods. 3rd ed. Thousand Oaks, CA: Sage Publications; 2002. xxiv, 598, 65 p. p.

26. Centers for Medicare and Medicaid Services, US Department of Health and Human Services. QPP Participation Status. 2020. Available from: https://qpp. cms.gov/participation-lookup. Accessed April 9, 2020.

27. Crossing the Quality Chasm: A New Health System for the 21st Century. Washington, DC. 2001.

28. The development and implementation of quality improvement systems (QIS) in health care. Strasbourg: Council of Europe; 1997. Recommendation No. R(97) 17 adopted by the Committee of Ministers of the Council of Europe on 30 September 1997 and explanatory memorandum.

29. Arah OA, Westert GP, Hurst J, Klazinga NS. A conceptual framework for the OECD Health Care Quality Indicators Project. Int J Qual Health Care 2006; 18 Suppl 1:5-13.

30. World Health Organization. Handbook for national quality policy and strategy: a practical approach for developing policy and strategy to improve quality of care. Geneva, Switzerland: World Health Organization; 2018.

31. European Commission. Key findings and recommendations on reporting and learning systems for patient safety incidents across Europe. Report of the reporting and learning subgroup of the European Commission. 2014.

32. In: Busse R, Klazinga N, Panteli D, Quentin W, eds. Improving healthcare quality in Europe: Characteristics, effectiveness and implementation of different strategies. European Observatory Health Policy Series. Copenhagen (Denmark); 2019.

33. Centers for Medicare and Medicaid Services, US Department of Health and Human Services. Consumer Assessment of Healthcare Providers and Systems (CAHPS) for the Merit-based Incentive Payment System (MIPS) Survey via CMS-Approved 
Survey Vendor Reporting. 2019. Available from: https:/qpp.cms.gov/resource/CAHPS\%20for \%20 MIPS\%20Fact\%20Sheet. Accessed May 4, 2021.

34. Centers for Medicare and Medicaid Services, US Department of Health and Human Services. CAHPS for MIPS Survey. 2020. Available from: https://www.
cms.gov/Research-Statistics-Data-and-Systems/ Research/CAHPS/mips.html. Accessed April 9, 2020.

35. Khullar D, Wolfson D, Casalino LP. Professionalism, performance, and the future of physician incentives. JAMA 2018;320:2419-20. 


\section{Appendix A1: Pre-Session Survey and Semi-} Structured Interview Guide Pre-Session Survey

1. Do you consider yourself a primary care physician? a. Yes

b. No

2. Are you licensed to practice medicine by the Medical Board in your state?
a. Yes

b. No

3. Are you board certified in internal medicine or family medicine?

a. Yes - internal medicine

b. Yes - family medicine

c. No

4. How many physicians are in your practice group? (To clarify, I consider your group to be a collection of physicians who bill under the same taxpayer ID number.)
a. 1 (solo practice)
b. 2 to 14 (small group)
c. 15 or more (large group)

5. How many years have you practiced medicine (since finishing your training)?
a. $<5$
b. 5 to 10
c. 10 to 15 days. 15 to 20
e. $>20$

6. Which of the following best describes your practice environment?
a. Urban
b. Suburban
c. Rural

7. About what percent of your patients are covered by Medicare?
a. $0 \%$
b. 1 to $9 \%$
c. 10 to $19 \%$
d. 20 to $29 \%$
e. 30 to $39 \%$
f. 40 to $49 \%$
g. $>=50 \%$
h. I do not know

8. About what percent of your patients face significant financial challenges such as housing and utility instability or having enough food to eat?
a. $0 \%$
b. 1 to $9 \%$
c. 10 to $19 \%$
d. 20 to $29 \%$
e. 30 to $39 \%$
f. 40 to $49 \%$
g. $>=50 \%$
h. I do not know

9. How large is your panel of patients?
a. $<1000$
b. 1000 to 1500
c. 1500 to 2000 days. 2000 to 2500
e. $>2500$
f. I do not know

10. Which of the following best describes how you are paid for patient service?

a. Fee-for-service
b. Capitation
c. Salary
d. Other:

11. What percentage of your income related to patient encounters comes from fee-for-service

payments?

a. $0 \%$

b. 1 to $24 \%$

c. 25 to $49 \%$

d. 50 to $74 \%$

e. 75 to $99 \%$

f. $100 \%$

g. I do not know

12. Do you have staff on hand that help you review and manage quality of care?

a. Yes. If yes, please describe their training or educational background

a. No

b. I do not know

13. Did you or your group participate in Medicare's

Physician Quality Reporting System, also known

as PQRS?

a. Yes

b. No

c. I do not know

Semi-structured interview guide

Hello, Dr. _ Thanks so much for meeting with me today and agreeing to participate in this study.

Let us begin our discussion.

PART 1: Exploring the nature of health care quality

First, I'd like to hear about what you believe quality means in health care.

1. What do you consider to be "good" quality of care? What does it "look" like?

2. What is exceptional quality of care, and how is it different from good quality of care?

3. What is low quality care, and how is it different from good quality of care?

4. What kinds of things can a primary care physician do to ensure he/she is providing exceptional quality of care?

5. How do you know, given the constraints of a particular day, whether you have been able to meet your own expectations on quality for a particular patient?

6. What are aspects of your practice that limit your ability to improve quality? (eg, limited time with patients, goal to work on patient satisfaction, etc.)

7. How do you or your staff members track patients after a visit? What role, if any, does monitoring play?

\section{\#\#\#RESULTS FROM THE REMAINDER OF THIS GUIDE WERE PUBLISHED SEPARATELY\#\#\#}

\#\#\#SEE REFERENCE 23 ABOVE\#\#

PART 2a: Exploring experiences with quality measurement and pay-for-performance systems

Now, I'd like to learn about your past experiences with quality measurement programs. For example, you may be familiar with NCQA's HEDIS Program, 
IHA's Quality Measurement Program, Medicare's PQRS, or other quality improvement systems that measure your performance. Often, quality measures look at prevention and the management of chronic diseases, such as how often patients are getting recommended vaccines or cancer screening. Sometimes quality measures target outcomes, like hemoglobin A1C goals for diabetic patients.

8. Have you have participated in some kind of quality measurement or monitoring program? For instance, Medicare's PQRS? Has your own group or organization used quality measures to assess, monitor, or improve quality of care?

9. What has your experience been like with quality monitoring programs? (ie, positive or negative, and how so?)

10. What kinds of things make it hard to perform well on quality measures?

11. What kinds of things make it easier to perform well on quality measures?

12. To what extent do you think that quality scores accurately reflect the quality of care delivered?

PART 2b: Exploring experiences with MIPS

Let us change gears a bit to talk about a more specific policy. Some people have heard about this program and some haven't.

13. Have you ever heard of the Merit-Based Incentive Payment System, also known as MIPS?

13a. (If yes) Great.

13b. (If no) That is ok. Allow me to explain a bit.

In 2015, Congress passed MACRA, the "doc-fix" bill that stopped Medicare's SGR (Sustainable Growth Rate) and also started linking physician payment to quality in a few different ways. One of these quality payment links is the new Merit-Based Incentive Payment System (from now on we'll call it MIPS). This system requires physicians to submit data on quality of care to Medicare. Each physician, or his/her group, chooses quality measures, collects data, and submits it to Medicare. Then, Medicare assesses physician performance compared with peers nationally, and it increases reimbursement for those who performed well during a certain time period and decreases reimbursement for those who did not.

14. How familiar are you with MIPS?

In some practices, physicians are very involved in making decisions about things like MIPS, while in other practices, administrators do most of this work.

15 . How far along are you or your practice in preparing to respond to MIPS? What changes have occurred as a result? What other changes are you anticipating? Have you needed to make changes in administrative and support staffing? Have you hired consultants to help out?

16. How did you or your group choose which MIPS measures to submit? (Or how do you or your group plan on choosing them?)

17. Who manages the data? What kind of feedback do you receive about how you are performing on the measures?
18. How do you think the MIPS policy will affect your ability to care for your patients?

19. How do you think this policy will affect quality of care for your patients?

Now, think about quality scores in MIPS. Physicians receive higher scores if they perform better on quality measures and lower scores if they do not perform as well.

20. To What Extent Do You Think That Quality Scores Reflect Quality of Care?

21. If a physician makes his or her score better or worse the next year, what does that mean for the quality of care that he or she provides?

Some people believe that the quality of health care is best measured by using health outcomes, such as mortality and morbidity.

22. How do you think this policy will affect health outcomes like morbidity and mortality for your patients?

PART 3: Exploring practice changes occurring as a result of MIPS

Now I'd like to talk about how this policy has affected you and your practice environment.

23. What changes have you or your practice made because of the policy? (or what changes do you anticipate needing to make?)

24. To what extent do you think that quality scores demonstrate true gaps in the care a physician provides? To what extent do you think quality scores can be improved by documentation rather than actual practice change? How do you think other doctors might try to game the system?

25 . How much would your annual income have to change to motivate you to improve your scores?

26. To what extent has this policy changed the way you spend your time on a typical day, if at all?

27. To what extent has this policy changed your relationship with your patients, if at all?

28. To what extent has your conception of the quality of care you provide changed as a result of this

policy? (ie, Do you know think you rank better or worse compared with other physicians?)

29. To what extent do you believe this policy changed power dynamics between PCPs and other physicians, if at all?

30. Imagine the opportunity arises to join a larger organization that has a team focused on quality measurement, allowing you to concentrate more on patient care. How attractive does that opportunity sound to you, everything else being equal?

31. How do you think the MIPS system could be improved?

32. In 5 to 10 years, what do you think doctors and patients will say about MIPS?

Thank you so much for sharing your thoughts and your time. I really appreciate it. 


\section{Appendix A2: List of Representative Quotes for Themes and Sub-themes}

Theme Sub-Them

Delivering evidencebased care that is safe
Providing recommended health maintenance

Controlling chronic diseases

Knowing and following current recommendations

Making accurate diagnoses

Delivering efficient care (not too much or too little)
"I believe that there are certain elements of providing care that are standard of care and that are proven to be beneficial to patients. Flu vaccine, pneumonia vaccine, vaccines in general, cancer screenings, like breast screening, colon cancer screening, cervical cancer screening." (P4)

"To deliver high-quality healthcare, first you have to talk about annual screening." (P2)

"For example, you have to make sure that patients are screened for colon cancer appropriately, for breast cancer, cervical cancer, that they're getting their vaccinations, that they are meeting the blood pressure goals." (P6)

"When people have certain chronic diseases there are certain measures that are just proven, like having an A1C that's as close to normal, having blood pressure at certain levels, having cholesterol-being on certain medications when you have certain chronic diseases-I think those things are quality to me." (P4)

"When a physician is taking care of a patient with diabetes... the patient should come in at 1 month, then 3 months, then 6-month intervals. [The physician] should know what blood work they're getting at that interval. At every visit, [the physician] should take off their shoes and socks, check monofilaments on them, make sure that the medications are reconciled, and that this information is communicated with the patient's other physicians. This should be a set protocol." (P12)

"I think good quality care has to be evidence-based. That's considered the standard of care." (P3)

"Lifelong learning and staying engaged with the latest literature, guidelines, and evidence-based recommendations [can help physicians provide high-quality healthcare].” (P16)

"Do the basics really well. Like getting everyone who has diabetes to have an A1C less than 9\%, people's blood pressure less than 140/90, just the things that you-except for the small number of cases-you should be able to help patients to get to." (P15)

"I would say that practices making every effort to ensure that they are meeting the standard of care as put forth from well-established bodies such as US Preventive Services Task Force, from CMS, and from our own organizations such as the American Academy of Family Physicians." (P6)

"Part of the key to being a good doctor is making the right diagnosis." (P7)

"Everybody can do checklist medicine and check [a hemoglobin A1C] twice this calendar year. [On the other hand,] when you have a patient with a difficult diagnosis which you establish and come up with an effective treatment for-now that's good care." (P11)

"If you ever come up with a diagnosis that someone else had missed, I think that's when I think high-quality care." (P7)

"High-quality care is medical care that's a universal standard, done in an efficient way that minimizes costs." (P12)

"My grandma was a very wealthy person, and she was very demanding. Basically, she would want you to forget about standards in healthcare and spend every healthcare dollar on her and waste everything on her to get every test possible, which is absolutely not right." (P12)

"What I learned is that quality equals appropriateness times the combination of outcomes and service and then dividing that by waste. I kind of like thinking about it as an equation-based definition.” (P15) 


Theme Sub-Theme

Delivering patient- $\quad$ Providing personalized care centered care

"I think I include the patient in all the decision-making. I present it to them like a buffet, where they get to pick and choose. I'll say, 'You know, at this age, I would love for you to have these three screening tests.' Then, they may say, 'I don't want to have a colonoscopy. What are my options? Can I have a stool test?' I would say that incorporating them into the decision-making is all about establishing a good relationship." (P1)

"Quality of care is all the care you need and none of the care that you don't need, delivered in a personalized way. .. working within the flow of patients' lives." (P16)

Providing well-coordinated care

Providing timely care

Spending enough time with patients

Responsiveness to patient concerns
"About $20 \%$ of our patients are non-English speaking....So, also making sure that care is coordinated well so that all pieces of the care get accomplished and get coordinated in a way that it's doable for the patients and also provides a good health outcome is challenging." (P9)

"I think developing systems as an individual or with teams in your clinic to ensure good follow-up for patients. So, seeing patients and tracking patients over time-Looking across your panel. . . and trying to be systematic and proactive about having patients come back in or refer to sites of care expeditiously and effectively." (P16)

"I can see records on a lot of different systems. So that kind of coordination of care is really important, in terms of making sure that we know what's going on with our patients. ...It requires a little bit of diligence, just making sure that your support staff, your medical assistants, whoever it is that's tracking down records, that they're doing that." (P19)

"I was very satisfied with the process because we're fortunate enough to have a referral team within our clinic so that I could get him to this study, then get the biopsy, the pathologist's report, and get him into the oncologist's office so that he was being treated within 5 days of the original study." (P20)

"You have to connect all the dots for the patients so that they have less to think about and less to worry about." (P12)

"I personally give my patients my email address so they can directly contact me with any concerns without being filtered by my staff. I try to have good hours, leave slots for urgent care, essentially have them be able to access me so that they can get care." (P1)

"It's more and more incumbent on doctors to manage your staff. . . so that if someone calls and they have a reason they need to get in, we need to do everything we can do to get them in." (P5)

"There are some primary care physicians who are seeing outrageous numbers of patients a day. 30, 40, and I'm doing about half that at most. ...I have time to review everything while I'm there. So, for example, if they're there for a hypertension visit and I'm adjusting their medications, I can also say, 'Ok, let me make sure you're up-todate with your mammogram, with your colonoscopy, and I'll take a look at your vaccinations." (P6)

"I think a good doctor has to spend enough time with the patient. Doctors shouldn't overbook themselves, and that means they have to be choosey about what insurances they accept." (P7)

"The key for most primary care doctors I believe is generally spending enough time, being responsive, and being accessible." (P3)

"Sometimes the difference between a good outcome and a bad outcome is just someone who is really paying attention." (P4)

"I think we want to provide healthcare for each individual, and we want to provide healthcare that addresses their needs." (P17)

"For me, good quality care is really trying to hear the patient out. ..Do they have any new or active issues that need to be addressed and then if so, properly addressing them." (P1) 
Being an advocate for patients

Understanding social needs

Helping patients achieve their goals

Prioritizing quality of life

Listening to patients

Educating patients

Establishing trust and longterm relationships
"When I think of a doctor who is exceptional, I think of someone who is an awesome patient advocate who makes sure that patients get what they need." (P4)

"I had a patient who was scheduled for a 15-minute visit on Saturday for a red swollen leg. [After getting a lower extremity ultrasound and a chest CT that were both positive for clots done from clinic], we directly admitted her from clinic. The patient was really grateful. It's not often that I get to deliver really good care like that but I definitely felt like it was high-quality because we bypassed the ED. She didn't have to go sit there for hours before being seen." (P15)

"Our population of patients have [poorly reimbursing insurance], don't speak English, don't have stable housing, and have been to jail. So, we definitely think about [food and housing security] first before we are able to get them their blood pressure medication and that sort of stuff." (P17)

"When I have patients who have certain socioeconomic challenges, it may be that they're homeless and it doesn't make sense to have them on nine medications a day for their heart failure, because there's no way they can possibly be compliant with it." (P5)

"Having a person or system or team that is able to meet individual [needs and concerns], that's exceptional care." (P17)

"I think our job as doctors is to help patients achieve their life goals, their health-related life goals. So for me, that's what quality is about....At the end of the day, if I'm achieving perfect scores [on quality measures] but not meeting the patients' goals, helping advance what they want, I'm not doing a good job." (P5)

"You have to keep the patient happy. I mean, they should be productive and happy and carrying on their daily living." (P2)

"The goal is to help patients achieve a better quality of life, and that is basically having people be as active as they want to be, having people be productive members of society, having them enjoy going for a walk." (P10)

"A lot of time it's balancing quality of life versus longevity and frequently we will opt for a shared decision-making process to focus more on quality of life, which may mean foregoing many recommended treatments, including certain ones that would achieve higher quality measure scores." (P5)

"I think the patients are looking for someone who will listen, someone who seems to be interested in the problems that they're presenting.... Obviously, they want you to be knowledgeable and compassionate and timely and everything else. But I think patients want to be listened to and taken more seriously than anything else." (P20)

"I think the important thing about patient care is about hearing people and really listening, letting them know that you're there." (P1)

"It comes down not only to making an accurate diagnosis but also making sure that the patient understands [the rationale with the care plan] and is on board with it-and that's frankly one of the more difficult things to do these days." (P11)

"The patient population we serve here-We have to hold them by the hands....You hold them by their hands and you educate them. They're going to be like, 'Why do I have to take my blood pressure medication when I feel okay?' So, it's all about education, education, education." (P13)

"Any time I see a patient, they're my number one priority. We are engaged and so, their perception of my time with them... whether I spend two minutes with them or 10 minutes with them, they always thought I spent enough time....So then what happens when people are satisfied is they go around and they tell their neighbors and they tell the family and so I have more patients coming in to be established and so on." (P10) 
Demonstrating compassion

"What people don't get is that if patients go to the person that they trust, they're more likely to be adherent to their medication or adherent to whatever regimen, if they know and trust the physician. I just think that's not there with virtual medicine or Uber docs or whatever." (P1)

"The quality movement has been perverted to a kind of big data enterprise now and really, I think the focus of primary care is actually about relationships and building sort of meaningful relationships with people over time....My quality metric-definition of quality is really much more around interpersonal relationships." (P18)

"There was this patent who just passed with severe COPD and she lived to be 86 with a disease that should have potentially taken herin my mind, she should have gone 10 years ago. But you know, we kept in close contact. There's this human component that's hard to measure, the connection that people feel with their primary care doctor for those who feel connected." (P10)

"I think that you have to be aware, first and foremost, for meeting a quality standard for all your patients but you also have to make sure that you have a heart for them as well. There is real truth to the statement that there is an art form in addition to the hard, basic science." (P6) 
Appendix A3: Participant-level Characteristics

\begin{tabular}{|c|c|c|c|c|c|}
\hline $\begin{array}{l}\text { Participant } \\
\text { number }\end{array}$ & $\begin{array}{l}\text { Practice } \\
\text { size }\end{array}$ & $\begin{array}{l}\text { Practice } \\
\text { setting }\end{array}$ & Compensation & Region & $\begin{array}{l}\text { Patient Panel } \\
\text { Size }\end{array}$ \\
\hline P1 & Large & Urban & Salary & West & 2500 or more \\
\hline $\mathrm{P} 2$ & Small & Urban & Capitation & West & $2000-2499$ \\
\hline P3 & Small & Suburban & Fee-for-service & West & $<1000$ \\
\hline P4 & Large & Urban & Fee-for-service & West & $<1000$ \\
\hline P5 & Large & Urban & Salary & West & $<1000$ \\
\hline P6 & Small & Urban & Capitation & West & $1000-1499$ \\
\hline P7 & Small & Suburban & Fee-for-service & West & 2500 or more \\
\hline P8 & Small & Rural & Fee-for-service & Midwest & $1500-1999$ \\
\hline P9 & Small & Rural & Salary & West & $<1000$ \\
\hline P10 & Large & Suburban & Fee-for-service & Midatlantic or Northeast & 2500 or more \\
\hline P11 & Large & Suburban & Fee-for-service & Midwest & 2500 or more \\
\hline P12 & Large & Urban & Salary & $\begin{array}{l}\text { South Midatlantic or } \\
\text { Northeast }\end{array}$ & $<1000$ \\
\hline P13 & Small & Rural & Fee-for-service & South & $<1000$ \\
\hline P14 & Small & Rural & Fee-for-service & South & 2500 or more \\
\hline P15 & Large & Urban & Salary & Northwest & $1000-1499$ \\
\hline P16 & Large & Suburban & Salary & Northwest & $<1000$ \\
\hline P17 & Large & Urban & Salary & Northwest & $<1000$ \\
\hline P18 & Large & Urban & Salary & Northwest & $<1000$ \\
\hline P19 & Small & Suburban & Salary & Northwest & 1000-1499 \\
\hline P20 & Large & Rural & Fee-for-service & West & 1500-1999 \\
\hline
\end{tabular}

